\title{
American Diabetes Association 2019 Conference Podcast With the Editor-in-Chief: What Are the Outcomes from ADA This Year and What Are the Future Developments in Diabetes?
}

Fernando Ovalle

Received: June 19, 2019 / Published online: July 2, 2019

(c) The Author(s) 2019

Keywords: Cardiovascular; Diabetes; Podcast; Precision Medicine; Research; Technology

My name is Fernando Ovalle. I am a professor of medicine, the director of the Division of Endocrinology, Diabetes and Metabolism at the University of Alabama at Birmingham in the USA, and I'm the US Editor-in-Chief for Diabetes Therapy.

I have spent the last 3 days at the ADA [American Diabetes Association] conference in San Francisco listening to different lectures and participating in meetings and I have learned quite a few interesting things.

So the big takeaway messages from the ADA for me are a few clinical trials that continue to show that some of the new drugs that we have

Enhanced Digital Features To view enhanced digital features for this article go to https://doi.org/10.6084/ m9.figshare.8293859.

Electronic Supplementary Material The online version of this article (https://doi.org/10.1007/s13300019-0661-z) contains supplementary material, which is available to authorized users.

F. Ovalle $(\square)$

Division of Endocrinology, Diabetes and

Metabolism, University of Alabama at Birmingham,

Birmingham, AL, USA

e-mail: fovalle@uab.edu for diabetes have important effects in cardiovascular events and kidney disease.

\section{WHAT IS THE MOST INTERESTING DATA YOU HAVE SEEN RELEASED AT THE CONFERENCE AND WHY?}

The most interesting data to me released during this conference include the REWIND [Researching Cardiovascular Events With a Weekly Incretin in Diabetes]; the REWIND trial was a trial in which the patients were assigned to either dulaglutide, which is a GLP-1 [glucagonlike peptide- 1 receptor] agonist, or placebo, and they were looking at the effects in cardiovascular outcomes. Now, this trial was a little bit different from others because of the type of patients that were involved: they were perhaps a little bit younger than patients in other cardiovascular outcomes trials and they could have or not have cardiovascular disease; most of them have enough cardiovascular risk factors. So it was a little bit more of a real-world trial if you will. This trial actually showed that dulaglutide, just like some of the other GLP-1 agonists, can reduce major adverse cardiovascular events. The reduction was not huge but I think the fact that it was able to achieve that goal in this population is quite significant. It also pointed to the fact that there was a significant reduction in 
strokes, and I think this is something that we are seeing in most of these GLP-1 outcome studies-that stroke rates seem to be lower and maybe driving some of these overall outcomes, the MACE [major adverse cardiac event] outcomes, and they actually complement really well what the SGLT2 [sodium-glucose cotransporter protein 2] inhibitors are doing because these seem not to fare as well in terms of stroke in their cardiovascular outcome trials; I think that's some of the most interesting data that I've seen here.

\section{WHAT ARE THE MOST IMPORTANT DEVELOPMENTS IN DIABETES RESEARCH CURRENTLY?}

The most important developments in diabetes currently I think are those in the area of precision medicine. I think there has been a lot of interest in that over the last few years, but until now we hadn't seen so much discussion about it in the scientific meetings, and there were several sections for precision medicine in diabetes on this course, and as matter of fact the presidential address touched on that quite a bit. And then the Banting Medal recipient, Professor O'Rahilly, also discussed it as some of his own research and findings are very much in that area. So I think there's a lot of interest in that area of research, which is taking off.

I think precision medicine in diabetes is very interesting because that is another way of looking at how to manage patients with diabetes; you know, we tend to perhaps be too fixed on determining "Okay, what do they have, type 1 diabetes or type 2 diabetes?" and we offer to simplify their diagnosis. Precision medicine makes us think about diabetes as a much more heterogeneous disease. It is possible that we may not be able to put people in precise diagnostic pockets all the time, but it's important to think about their likely outcomes. And we start thinking about diabetes in how they may respond to therapies differently and how can we change their outcomes in the individual patient as opposed to as a, just to say, group in general? We will be doing a service to our patients and it is very likely that some patients with type 2 diabetes will respond better to certain drugs in terms of reducing the risk of having strokes or heart attacks in the future than other subsets of patients and while me not we may not be able to find their exact cause we may be able to find which patients respond better to what drugs and thus be able to prevent disease and complications a little better.

\section{WHERE DO YOU SEE DEVELOPMENTS IN DIABETES RESEARCH AND CARE IN THE FUTURE?}

Where I see the developments in research and care in the future are in the area of cardiovascular disease outcomes. I think that's where we're going to continue to see advances and therapies are addressing those needs. You know, we're no longer just thinking about "well we're going to reduce the glucose, we've got to normalize glucose" but we have to be thinking more about how can we make the patients' lives better and longer, and that's by reducing their complications. In some patients, it may not matter as much to reduce their glucose level as much as it may matter to put them on the drug that we know will give them the biggest risk reduction in terms of complications in the long term. So that's I think the area we are going to see changes.

We, as always, have new therapies that are being developed and I think there are several interesting therapies. The combination of GLP1 receptor agonist with the GIP [glucose-dependent insulinotropic polypeptide] agonist is an interesting one. The glucagon story is another very interesting one. So I think there are several areas that are developing fast.

\section{WHAT QUESTIONS DO WE STILL NEED TO ANSWER IN DIABETES?}

Well, there are still a lot of questions to be answered; we still know very little about diabetes in general. We would like to understand why people develop diabetes, who is at risk, and 
be able to predict that and prevent it. We want to prevent complications; we want to have better therapies.

So there is a lot of questions in just about every area of diabetes, but we're making small steps and progress towards that. There is another area that I think is important that I perhaps have not mentioned and this is technology. Technology is moving at a faster pace than pharmacology and other areas in the research of diabetes, and that may have to do with the funding, that may have to do with the way regulatory agencies allow things to progress, but some of these devices-the insulin pumps and the continuous glucose monitorsare improving really fast and it would not be long from when we have a fully functioning automated pump that we just put on the patient and we don't have to enter any data other than perhaps their weight and the pumps will fully control their blood glucose. That I think is within the next 5 years, perhaps even less, and I think machine learning is going to help a lot in that area as well. So, there are very exciting things happening in diabetes technology.

\section{ACKNOWLEDGEMENTS}

This commentary is authored by the Editor-inChief of the journal and, contrary to the journal's standard single-blind peer review process, it has not been peer-reviewed.
Funding. No funding or sponsorship was received for this study or publication of this article.

Authorship. The author meets the International Committee of Medical Journal Editors (ICMJE) criteria for authorship for this article, takes responsibility for the integrity of the work as a whole, and has given his approval for this version to be published.

Disclosures. Fernando Ovalle has nothing to disclose but is the Editor-in-Chief for Diabetes Therapy.

Compliance with Ethics Guidelines. This article does not contain any studies with human participants or animals performed by any of the authors.

Open Access. This article is distributed under the terms of the Creative Commons Attribution-NonCommercial 4.0 International License (http://creativecommons.org/licenses/ by-nc/4.0/), which permits any noncommercial use, distribution, and reproduction in any medium, provided you give appropriate credit to the original author(s) and the source, provide a link to the Creative Commons license, and indicate if changes were made. 